\title{
A epigenética como nova hipótese etiológica no campo psiquiátrico contemporâneo
}

\section{| ${ }^{1}$ Luna Rodrigues Freitas-Silva, ${ }^{2}$ Francisco Javier Guerrero Ortega |}

Resumo: Nas últimas décadas, as teorias neurocientíficas passaram a ser adotadas como explicação primordial para a etiologia dos transtornos mentais. Com o objetivo de encontrar os fundamentos dos transtornos, as investigaçôes priorizaram a carga genética e o funcionamento cerebral. A partir da valorização da determinação biológica das doenças e do surgimento de variadas tecnologias de pesquisa médica, aventou-se a possibilidade de que as causas dos transtornos fossem, finalmente, compreendidas. No entanto, diversas dificuldades e desafios marcam o projeto neurocientífico de fundamentação biológica da etiologia das doenças. A introdução recente da noção de epigenética no campo psiquiátrico vem sendo considerada fundamental para renovar a esperança de compreensão da etiologia dos transtornos. A partir da análise de artigos de revisão, o presente trabalho tem como objetivos examinar a apropriação da noção de epigenética pelo campo psiquiátrico contemporâneo, identificando suas origens e descrevendo suas principais características, e refletir sobre as consequências de sua adoção. Além de contribuir para a redefinição das teses etiológicas no campo psiquiátrico, a noção de epigenética impõe uma reconfiguração do conhecimento genético e, em certa medida, do próprio projeto determinista e reducionista de fundamentação biológica dos transtornos mentais, permitindo interpretações mais nuançadas sobre as neurociências e a psiquiatria contemporânea.

> Palavras-chave: Psiquiatria biológica; neurociências; etiologia.

\footnotetext{
1 Departamento de Psicologia, Universidade Federal Rural do Rio de Janeiro. Seropédica-RJ, Brasil. Endereço eletrônico: lunarodrigues@yahoo.com.br

2 Instituto de Medicina Social, Universidade do Estado do Rio de Janeiro. Rio de Janeiro-RJ, Brasil. Endereço eletrônico: fjortega2@gmail.com
} 
As teorias neurocientíficas construídas nas últimas décadas vêm se destacando como explicação primordial para a formação da patologia mental, ocupando lugar central no campo psiquiátrico e motivando maciços investimentos financeiros e intelectuais. Neste contexto, chamado por Shorter (1997) de "segunda psiquiatria biológica”, predominam abusca pelossubstratos biológicos da doença, especialmente por meio da valorização de uma abordagem científica, objetiva e reducionista das patologias mentais, e a valorização das intervençōes medicamentosas, consideradas as ações psiquiátricas propriamente ditas (SHORTER, 1997; HEALY, 2002; HOROWITZ, 2002; EHRENBERG, 2004; MAYES; HOWITZ, 2005; ABIRACHED; ROSE, 2010; ROSE; ABI-RACHED, 2013).

Do ponto de vista histórico, pode-se afirmar que osurgimento das neurociências, por volta dos anos $1960,{ }^{1}$ e a reorientação da psiquiatria em direção à busca pelos determinantes físicos e objetivos das doenças, nos anos 70 e 80 , inauguraram um período de predominância das hipóteses biológicas sobre a formação patológica (SHORTER, 1997; EHRENBERG, 2004; MAYES; HORWITZ, 2005). Com a chamada remedicalização da psiquiatria, os transtornos mentais passaram a ser entendidos como resultado de fenômenos biológicos determinados e acessíveis por meio das estratégias reducionistas de investigação científica, em contraposição às explicações psicológicas e ambientalistas e à respectiva valorização de discursos e práticas que tomavam o indivíduo como ponto de partida, que vigoraram durante algumas décadas no campo psiquiátrico.

Dois componentes se destacam nas pesquisas neurocientíficas recentes: o genético e o cerebral. Com o objetivo de encontrar os fundamentos biológicos das patologias mentais, as investigações das últimas décadas tomaram como alvos a carga genética e o funcionamento cerebral dos indivíduos, considerados elementos-chave para a compreensão da psicopatologia. Com o surgimento de diversas tecnologias médicas, as pesquisas genéticas e cerebrais avançaram, inaugurando a possibilidade de investigação de mecanismos moleculares ínfimos, e passaram a gerar um acentuado otimismo. A partir da valorização da determinação biológica das doenças e do surgimento de variadas tecnologias de pesquisa médica, aventou-se a possibilidade de que as causas dos transtornos mentais fossem, finalmente, compreendidas (INSEL; QUIRION, 2005). 
Se os avanços conquistados por tais pesquisas no que se refere ao entendimento de mecanismos genéticos específicos e de características fundamentais da morfologia e da fisiologia cerebral são inegáveis, no que diz respeito à compreensão da emergência dos transtornos mentais, diversas dúvidas e dificuldades permanecem mobilizando o campo. Afinal, como se formam os transtornos mentais? Quais são suas principais causas? De que modo a determinação genética produz o funcionamento cerebral anormal? Quais são, efetivamente, os processos cerebrais subjacentes a cada transtorno? Como um determinado funcionamento cerebral produz as experiências subjetivas que entendemos como sintomas? Como tratá-los? Como preveni-los? Tais questôes, longe de terem sido respondidas, permanecem em cena, motivando pesquisas e gerando discussão.

Diante dos desafios que envolvem a compreensão da etiologia dos transtornos mentais no âmbito das pesquisas neurocientíficas, novos operadores conceituais vão sendo construídos como estratégia para fazer avançar o projeto psiquiátrico de fundamentação biológica das patologias mentais. Ao analisarmos as produções da psiquiatria contemporânea, identificamos o destaque de determinadas formulações conceituais e a emergência de alguns temas de pesquisa, que parecem estar contribuindo para a formação de um novo modelo etiológico das patologias mentais. Neste contexto, a introdução recente da noção de epigenética no campo psiquiátrico vem sendo considerada fundamental para explicar o funcionamento cerebral e, consequentemente, a etiologia dos transtornos. No entanto, se a noção de epigenética fornece novo fôlego às pesquisas neurocientíficas, ela também gera consequências inesperadas, como o redirecionamento dos principais alvos da investigação, o redimensionamento da determinação genética e a reconfiguração das relações entre biologia e ambiente (SINGH, 2012; ROSE; ABI-RACHED, 2013; ROSE, 2013).

A partir da análise de artigos de revisão, o presente artigo tem como objetivos analisar a apropriação da noção de epigenética pelo campo psiquiátrico contemporâneo, buscando identificar suas origens e descrever suas principais características, e refletir sobre as consequências dessa apropriação para a emergência de novas hipóteses etiológicas dos transtornos mentais. Para tanto, foi realizada uma pesquisa de artigos na base de dados Pubmed, utilizando como critério os termos "epigenetics" e "psychiatry", e data de publicação entre 2000 e 2011. Inicialmente foram selecionados os artigos de revisão, que apresentam uma 
compilação dos resultados encontrados nos artigos originais de pesquisa. A partir do conteúdo destes artigos, novas referências foram incorporadas à análise.

\section{A origem da hipótese epigenética}

Os mecanismos epigenéticos vêm sendo considerados uma das principais apostas da pesquisa atual em psiquiatria, pois representariam um modelo de explicação da doença fundamentalmente biológico e, mais especificamente, capaz de descrever a etiologia dos transtornos a partir do nível molecular. O modelo considera a interação entre a herança genética do indivíduo e os fatores ambientais, analisando esse processo como alterações intracelulares na expressão do material genético do organismo, que culminam na determinação das características exibidas pelo indivíduo. Os mecanismos epigenéticos dizem respeito, fundamentalmente, aos meios e processos pelos quais a determinação biológica do organismo é atualizada e expressada ao longo de seu desenvolvimento (HAIG, 2004; GOTTESMAN; HANSON, 2005; HOLLIDAY, 2006; RUTTER; MOFFITT; CASPI, 2006; JIRTLE; SKINNER, 2007; BORRELLI et al., 2008; TSANKOVA et al., 2007; GWAS, 2009; NESTLER, 2009; SWEATT, 2009; DICK; RILEY; KENDLER, 2010; DUDLEY et al., 2011; MURGATROYD; SPENGLER, 2011; ROTH; SWEATT, 2011).

O conceito de epigenética surgiu nos anos 1940, com o biólogo Conrad Waddington, para descrever a interação entre genes e ambiente que permite o surgimento dos fenótipos. Em artigo publicado em 1942, Waddington demonstrava interesse pelos processos que permitem que o genótipo, a carga genética do organismo, conduza ao aparecimento de efeitos fenotípicos, as características expressas do organismo. Tratava-se de investigar um tema que inquietava os geneticistas da época e que relacionava o estudo genético ao processo de desenvolvimento. Segundo Waddington (1942), para compreender a relação entre a herança genética e os processos de desenvolvimento, seria necessário adotar duas medidas: a primeira, mais simples, consistiria na descrição dos processos de desenvolvimento observáveis; a segunda, mais importante, consistiria na investigação dos mecanismos causais em funcionamento nos processos observados, relacionando-os, sempre que possível, às descobertas reveladas pela embriologia experimental. Para essa segunda esfera de investigação, Waddington sugeria o termo "epigenética". 
Nesta primeira proposição, o estudo dos mecanismos epigenéticos surgia para suprir uma lacuna no entendimento da forma pela qual a carga genética conduziria à formação dos fenótipos ao longo do processo de desenvolvimento. No referido momento, sabia-se muito pouco sobre as propriedades da epigênese, e a suposição de Waddington era de que mecanismos específicos e complexos de desenvolvimento determinassem essa transposição, conectando o material genético às características do organismo. A intuição do autor era que o processo seria constituído por diversos mecanismos concatenados, articulados em rede, de modo que qualquer alteração em um estágio inicial poderia causar modificações graduais, mas contínuas, nos estágios seguintes, alcançando maior número de tecidos e órgãos e formando anormalidades no desenvolvimento. Portanto, Waddington apostava na regulação e no controle das diversas etapas do desenvolvimento embrionário pela carga genética do organismo.

Apesar de citar exemplos de fenômenos observados na formação das asas da Drosophila que sugeriam a intuição apresentada nesse artigo, Waddington não dispunha de evidências experimentais acerca dos mecanismos epigenéticos. De fato, essa primeira hipótese era uma suposição teórica, pois não havia qualquer experimento ou evidência científica que pudesse demonstrá-la. Segundo Holliday (2006), até a metade do século XX, a biologia do desenvolvimento e a genética eram dois domínios de pesquisa separados, com pouco contato entre si. Nesse contexto, a hipótese de Waddington tinha como objetivo construir uma ponte, inédita até então, entre os fenômenos observados no desenvolvimento de um organismo e sua constituição genética, aproximando os dois campos da biologia, aumentando a complexidade da explicação acerca da determinação genética dos organismos e atrelando-a aos processos de desenvolvimento, especialmente os característicos da fase embrionária.

Esta primeira intuição continuou sendo discutida por alguns poucos pesquisadores, sendo sempre utilizada para denominar fenômenos biológicos que, ao serem observados, não eram facilmente entendidos a partir do conhecimento genético disponível, mas que indicavam conter em seu funcionamento algum componente hereditário (HAIG, 2004; HOLLIDAY, 2006). Essas discussões pontuais sobre supostos mecanismos epigenéticos apareceram, por exemplo, nas pesquisas sobre câncer de Huxley (1956) e em revisões sobre hereditariedade e mecanismos de controle celular de Nanney (1958). Segundo Haig (2004), ao 
longo da década de 60, alguns estudos sobre câncer e cultura de células parecem ter utilizado ou derivado algumas de suas suposições da noção de epigenética, mas sempre de forma implícita ou indireta. Naquele momento, nenhum mecanismo mais específico havia sido proposto para descrever e qualificar a hipótese epigenética.

Posteriormente, nos anos 70, a primeira suposição foi elaborada e redescrita, pela primeira vez, como um fenômeno biológico específico: a epigenética seria uma alteração química do DNA, mais chamada de metilação. ${ }^{2}$ A primeira sugestão de que a metilação do DNA poderia ter um papel biológico importante, fornecendo a base para a formação da memória de longo prazo no cérebro, apareceu no artigo de Griffith e Mahler (1969). Em seguida, Riggs (1975) e Holliday e Pugh (1975) publicaram artigos que sugeriam um modelo molecular para a ativação da carga genética, englobando também a transmissão hereditária da atividade e inatividade de determinados genes. Em ambos os casos, a metilação do DNA era considerada um mecanismo potencialmente importante para variações na expressão genética, podendo explicar especificamente a ativação ou inativação de determinados genes durante o processo de desenvolvimento do organismo.

O artigo de Holliday de 1987 é considerado paradigmático no campo. Nele, o autor revisa o uso do termo "epignética" por Waddington e o utiliza para caracterizar fenômenos nos quais uma alteração na metilação do DNA acarreta alterações na ativação da carga genética, discutindo sua importância para o entendimento de fenômenos como o câncer e o envelhecimento. Para Haig (2004), esse artigo, publicado na revista Science, estimulou o interesse pelos fenômenos epigenéticos, contribuiu para a retomada do termo e inaugurou um movimento de alto investimento em pesquisas destinadas à sua investigação. $\mathrm{O}$ conceito de epigenética passa então a ser definido como o estudo de mudanças na expressão genética que ocorrem não em função de mudanças na estrutura do DNA, mas de alterações específicas na expressão de alguns genes, ou seja, nas substâncias que são produzidas a partir das informações de determinado gene (JIRTLE; SKINNER, 2007; BORELLI et al., 2008; SWEATT, 2009; TSANKOVA et al., 2007). Finalmente, em 1990, além de adquirir o vocabulário molecular que a caracteriza atualmente, a hipótese epigenética passa a ser sustentada por evidências experimentais surgidas em diversas pesquisas, que começam a proliferar, principalmente nos campos dos estudos genéticos sobre o câncer e da biologia do desenvolvimento. 
No entanto, podemos observar que a "revolução genômica" que pode significar

a descoberta e o entendimento de mecanismos epigenéticos representa, no caso específico das patologias mentais, não apenas avanços no conhecimento molecular e genético, mas também e, principalmente, a construção de soluções interessantes e de argumentos estratégicos para a dificuldade de se explicar a origem dos transtornos mentais. Nesse sentido, a apropriação do conceito de epigenética pelo conhecimento psiquiátrico aparece como recurso explicativo diante da decepção com a identificação de marcadores biológicos diretos nas pesquisas genéticas e de antigos resultados inconclusivos nos estudos epidemiológicos com transtornos mentais (MUNAFÓ, 2006; OH; PETRONIS, 2008; OS; RUTTEN; POULTON, 2008; NESTLER, 2009; RUTTEN; MILL, 2009).

\section{A complexidade genética dos transtornos mentais}

No que se refere à pesquisa genética, apesar do alto investimento e da elevada esperança de encontrar marcadores biológicos - no caso, os genes que determinariam as doenças - para os transtornos mentais, os resultados são, até o momento, decepcionantes. Um artigo de revisão do Psychiatric GWAS Consortium Coordinating Committee $e^{3}$ (2009) analisa os resultados de pesquisas genéticas realizadas no âmbito do projeto de mapeamento do genoma humano referentes aos transtornos mentais. Trata-se de um consórcio internacional que se reuniu para analisar de forma integrada as primeiras informaçōes disponíveis, resultantes de cerca de 50 pesquisas, sobre a genética dos transtornos psiquiátricos. ${ }^{4}$ Por meio de uma estratégia colaborativa, reunindo dezenas de grupos de pesquisa, pretendese ampliar o número de indivíduos acessados e aumentar o poder analítico e estatístico dos resultados alcançados. Com a combinação de resultados de dezenas de estudos, a amostra analisada adquire uma magnitude nunca antes alcançada nos estudos em genética humana - por exemplo, 10.000 casos comparados a 10.000 casos-controle (GWAS, 2009; SULLIVAN, 2010; VISSCHER et al., 2012).

A primeira consideração que se destaca nesse estudo diz respeito à complexidade genética suposta para as patologias mentais, nas quais o risco hereditário seria resultado da interação de variaçooes genéticas combinadas, cada qual com um impacto relativo limitado sobre o risco total. De fato, as primeiras pesquisas genéticas dos transtornos psiquiátricos analisavam amostras pequenas de sujeitos da mesma família com o objetivo de encontrar mecanismos genéticos simples. 
O desenho desses primeiros estudos, que apresentaram resultados conclusivos para centenas de outras doenças, foram pouco férteis para a compreensão e não geraram informação relevante acerca da fisiologia patológica de doenças complexas e multifatoriais, incluindo os transtornos mentais.

Novas pesquisas foram elaboradas, reunindo amostras maiores (centenas de famílias), mas os achados continuaram sendo pouco significativos ou difíceis de serem confirmados em novas pesquisas. Segundo a revisão do artigo do GWAS (2009), os resultados desses estudos são controversos, uma vez que algumas associações estatisticamente significativas entre um determinado gene e um transtorno foram encontradas, mas não foram confirmadas em pesquisas subsequentes. Ou seja, os resultados não puderam ser replicados e, portanto, confirmados por novas pesquisas genéticas.

A principal interpretação dos pesquisadores sobre esses primeiros resultados é que a impossibilidade de confirmação em novas pesquisas se deve ao fato de que o efeito do respectivo gene sobre a formação da patologia é restrito, ou seja, contribui para a etiologia, mas o grau de influência e determinação da doença é pequeno. Desse modo, a suposição de uma causalidade genética simples, do tipo "gene para o transtorno X", foi dando lugar à consideração de variações genéticas com impacto relativamente pequeno sobre o risco, e a suposição de uma maior complexidade genética dos transtornos. Podemos observar que o entendimento da causalidade genética se torna menos linear e mais probabilístico, com destaque para a noção de risco, que se mostra mais adequada para explicar os objetivos das pesquisas e interpretar as limitações dos resultados encontrados.

Alguns avanços conquistados no mapeamento genético de doenças complexas, como diabetes e obesidade, geraram novas hipóteses e métodos de pesquisa, posteriormente aplicados aos transtornos mentais. A hipótese de "múltiplas variações raras" surgiu nesse contexto e vem sendo utilizada como modelo das pesquisas atuais, informando a busca pelos marcadores genéticos em psiquiatria. Essa hipótese tem como foco as variações estruturais raras (as chamadas CNV, ou copy number variations), resultantes de perda (deleção) ou ganho (duplicação) de bases do DNA, que contribuem para a variabilidade genética normal, o risco para doenças, as anomalias do desenvolvimento e os mecanismos mutacionais presentes na evolução. Combinadas, as mudanças sequenciais no material genético seriam responsáveis pelo risco para determinadas doenças (GWAS, 
RODRIGUEZ; LIU, 2011; KIM et al., 2011).

Em função deste entendimento acerca da limitação da determinação genética, a estratégia do Psychiatric GWAS Consortium Coordinating Committee consiste na realização de meta-análises de todos os resultados de pesquisas genéticas publicados para os transtornos selecionados, de modo que mesmo as associações mais remotas entre a carga genética e o aparecimento da patologia possam ser mapeadas. Considerando-se que a exposição à variação genética ocorre desde os estágios iniciais do desenvolvimento, o risco genético estaria no início da cadeia causal que conduz à doença, representando o primeiro elemento de um processo complexo e multifatorial.

Destacando a esquizofrenia como exemplo, uma vez que a categoria é alvo de diversas pesquisas e reúne considerável interesse, podemos observar a construção da lógica dos estudos e da interpretação dos resultados alcançados. De forma bastante resumida, pode-se dizer que algumas variações numéricas no material genético foram associadas com a esquizofrenia. Individualmente, essas variaçôes são raramente associadas à suscetibilidade para a esquizofrenia, indicando que o risco isolado das alterações é relativamente pouco significativo. A título de exemplo, duas pesquisas revisadas pelo artigo do GWAS encontraram associaçōes entre perda de material genético nos cromossomos 1q21.1 e 15q13.3 e o diagnóstico de esquizofrenia. No entanto, a prevalência das referidas alterações é de, respectivamente, 0,2\% e 0,3\%. Ou seja, entre os indivíduos diagnosticados com esquizofrenia participantes dos estudos, menos de $1 \%$ apresenta as alterações genéticas investigadas (GWAS, 2009).

Deste modo, ainda que o conhecimento desse tipo de variação genética agregue informaçôes sobre a formação de um transtorno como a esquizofrenia, sua capacidade diagnóstica, terapêutica ou preventiva se mantém muito limitada. O mesmo tipo de resultado vem sendo encontrado para outras categorias diagnósticas, sendo que a esquizofrenia é a categoria mais pesquisada, e sobre a qual o maior número de informações foi reunido até o momento (RUTTEN; MILL, 2009; GWAS, 2009; KIM et al., 2011). Os pesquisadores do campo continuam investindo nas pesquisas sobre a estrutura do DNA com o objetivo de construir mapas da arquitetura genética dos transtornos que possam, posteriormente, ser articulados a informações fisiopatológicas na composição da neurobiologia das 
doenças. No entanto, com a ausência de resultados significativos, conclusivos, que sejam efetivamente replicados em pesquisas subsequentes ou que tenham implicações mais diretas na terapêutica ou na prevenção, novos caminhos e hipóteses começaram a ser considerados. ${ }^{5}$

A baixa prevalência das variações genéticas para a esquizofrenia, bem como para outros transtornos mentais, ganha novo sentido a luz da hipótese epigenética. Uma vez que não foi possível identificar genes diretamente associados aos transtornos mentais, a lógica do "gene para o transtorno X" é substituída por novas hipóteses, noções e métodos de pesquisa, tanto no que se refere à consideração da combinação de variados genes na determinação da doença, quanto à investigação da interação entre diferentes fatores ambientais e a carga genética dos indivíduos. Como afirmam Kim et al. (2011), o objetivo das pesquisas genéticas passa a ser a identificação dos variados caminhos que conferem risco e proteção aos transtornos mentais. Assim, Sullivan (2011, p. 6) sugere que os resultados das próximas pesquisas devem consolidar essa hipótese, apostando que "os fatores de risco genético irão incluir um espectro de variações, desde variações raras com efeito forte, até variaçōes comuns com efeitos mais discretos".

\section{As pesquisas epidemiológicas e a influência do ambiente}

Ao mesmo tempo em que outros mecanismos genéticos e moleculares começam a ser explorados, os estudos epidemiológicos mantêm a busca pelos fatores ambientais que influenciam o surgimento das patologias mentais, mas adotando a mesma suposição da etiologia complexa que surge da interação gene-ambiente (JABLONKA, 2004; WONG; GOTTESMAN; PETRONIS, 2005; OS; RUTTEN; POULTON, 2008; OH; PETRONIS, 2008; FOLEY et al., 2009; RUTTEN; MILL, 2009; DICK; RILEY; KENDLER, 2010). Também no caso da pesquisa epidemiológica, a hipótese epigenética parece solucionar antigos problemas e questôes não resolvidas e pode, inclusive, redirecionar os objetivos e as características das investigações na área.

Historicamente, os estudos epidemiológicos em psiquiatria se ocuparam em distinguir os fatores ambientais dos fatores genéticos associados aos transtornos mentais, principalmente por meio de pesquisas com gêmeos, adoções e famílias de indivíduos portadores de transtorno mental. Uma das principais suposições das pesquisas epidemiológicas residia na diferença de ocorrência de transtornos 
mentais entre gêmeos monozigóticos: se os indivíduos possuem a mesma carga genética, as diferenças de ocorrência dos transtornos poderiam ser atribuídas à exposição a fatores ambientais não partilhados pelos irmãos. A pesquisa com gêmeos monozigóticos criados em ambientes distintos era uma das principais estratégias de pesquisa epidemiológica para identificar os fatores ambientais que conduziriam às doenças (WONG; GOTTESMAN; PETRONIS, 2005; OS; RUTTEN; POULTON, 2008; OH; PETRONIS, 2008).

Os estudos com indivíduos adotados representavam outra estratégia importante no campo da epidemiologia psiquiátrica, comparando as similaridades entre irmãos adotados por famílias distintas, que compartilham características genéticas, mas são criados em ambientes separados, e irmãos adotivos, que compartilham o ambiente, mas não a constituição genética (DICK; RILEY; KENDLER, 2010). Em ambos os casos, importava discriminar o impacto da herança genética na predisposição ao aparecimento da doença, e identificar os fatores ambientais que exercessem impacto sobre a formação psicopatológica. $\mathrm{Ou}$ seja, os principais objetivos das pesquisas eram identificar e, fundamentalmente, discriminar as influências ambientais e as influências genéticas na formação dos transtornos (OS; RUTTEN; POULTON, 2008; OH; PETRONIS, 2008; DICK; RILEY; KENDLER, 2010).

Tomando o caso da esquizofrenia como exemplo, Oh e Petronis (2008) relembram o resultado das pesquisas epidemiológicas das últimas cinco décadas, nas quais diversos fatores ambientais foram identificados como capazes de aumentar o risco para a esquizofrenia: estresse, abuso físico e mental, dieta materna durante a gravidez, uso de drogas, vida urbana, migração, entre outros. Além da identificação de fatores ambientais, a determinação da influência genética na esquizofrenia continuou sendo investigada, mas, como vimos, a ambição de encontrar um único gene que respondesse pela hereditariedade da doença não se confirmou nas pesquisas genéticas. Deste modo, ainda que as pesquisas epidemiológicas sejam importantes para a identificação de possíveis fatores que conduzem aos transtornos, tanto hereditários, como não hereditários, a evidência surgida acaba sendo descritiva, mas não explicativa dos mecanismos etiológicos da doença.

Como vimos, a possibilidade de identificar um gene que determine um transtorno psiquiátrico não se confirmou nas pesquisas realizadas no âmbito 
do projeto de mapeamento do genoma humano, o que acabou por conduzir à elaboração de novas hipóteses, com a recuperação do termo "epigenética" e o direcionamento das investigações para os fenômenos de "expressão da carga genética”. Além da dificuldade de verificação da hereditariedade genética, as associações encontradas nos estudos dos fatores ambientais que contribuem para o aparecimento da patologia somam pouco à compreensão dos nexos causais que a determinam. Ou seja, as associações não são suficientes para esclarecer os mecanismos etiopatológicos subjacentes aos transtornos se não forem atreladas a possíveis achados fisiológicos. ${ }^{6}$

Além do tipo de limitação própria aos estudos epidemiológicos, alguns desafios e complexidades metodológicas carecem de explicação - como exemplo, a recente associação entre esquizofrenia e uso de maconha. Segundo Oh e Petronis (2008), entre os diversos fatores ambientais pesquisados como risco para a esquizofrenia, o uso da maconha é um dos que vêm apresentando resultados mais significativos e estimulando diversas novas investigaçôes. Em uma meta-análise de sete pesquisas sobre essa associação, os resultados indicaram associação significativa entre uso de maconha e esquizofrenia (HENQUET et al., 2005, apud OH; PETRONIS, 2008). No entanto, como argumentam Oh e Petronis (2008), a interpretação dos resultados não pode ser simplista, e a descoberta da associação não necessariamente equivale à revelação de um nexo causal entre os dois fenômenos. Por um lado, a associação pode ser entendida como evidência de que o uso de maconha, um fator ambiental, aumenta o risco para o desenvolvimento da esquizofrenia, sugerindo relações de causalidade entre os dois fenômenos. Por outro, alguns pesquisadores questionam se, de fato, o uso da droga é um gatilho que desencadeia o transtorno ou se, como sugerem outras pesquisas e a experiência clínica com esses pacientes, pode representar uma estratégia de automedicação para fazer frente a sintomas psicóticos presentes em estado inicial.

Esse tipo de questão, que não pode ser facilmente respondida pela pesquisa epidemiológica, com a hipótese epigenética passa a ser redescrita como consequência de mecanismos epigenéticos e interpretada a partir da noção de risco. Além disso, e mais fundamental, o conceito de epigenética pode oferecer uma explicação molecular para os achados planos, estatísticos, provenientes dos estudos epidemiológicos, constituindo-se como explicação atraente e argumento estratégico no campo. Deste modo, diversas pesquisas epidemiológicas vêm 
adotando a hipótese epigenética e buscando identificar não somente os fatores ambientais, mas o modo como os mesmos interagem com a herança genética (JABLONKA, 2004; FOLEY et al., 2008; OS; RUTTEN; POULTON, 2008; OH; PETRONIS, 2008; DICK; RILEY; KENDLER, 2010).

Nesse contexto, o antigo objetivo de discriminar as influências do ambiente e da carga genética, diferenciando-os, começa a ceder lugar a questôes mais complexas, como a compreensão dos caminhos que conduzem ao risco e à interação dinâmica entre a herança genética e as influências ambientais a que é submetido o organismo. O projeto EU-GEI é um exemplo de pesquisa de grande porte em curso atualmente informada pela hipótese epigenética. Conduzido por pesquisadores do Reino Unido, Holanda, França, Espanha, Turquia e Alemanha, com a colaboração de outros países, financiado pela Comissão Europeia, o projeto EU-GEI se caracteriza como uma rede de pesquisas, realizadas ao longo de cinco anos (2010-2015), destinadas à investigação da epidemiologia, genética e clínica da esquizofrenia. De acordo com o site do projeto, a rede é formada por pesquisadores multidisciplinares, líderes na pesquisa da esquizofrenia, adota paradigmas metodológicos também multidisciplinares e pretende identificar os fatores epidemiológicos, clínicos e genéticos que influenciam o aparecimento, a severidade e a evolução da esquizofrenia.?

Para Dick, Riley e Kendler (2010), a epidemiologia genética, especialmente aquela destinada à compreensão dos transtornos mentais, vem passando por uma revolução nos seus objetivos e nos tipos de questão que usualmente organizam e motivam as pesquisas no campo. $^{8}$ Assim como as pesquisas em genética psiquiátrica foram sendo redefinidas em direção a uma maior complexidade genética, também o campo da epidemiologia psiquiátrica estaria se interessando pela interação entre os diferentes fatores etiológicos e adotando a hipótese epigenética como operador conceitual importante em suas recentes pesquisas.

\section{Algumas considerações sobre a noção de epigenética no campo psiquiátrico}

A despeito dos imensos investimentos e do grande otimismo gerado pelas promessas de determinação biológica dos transtornos mentais no contexto das pesquisas em neurociências, o efetivo entendimento dos processos de formação 
das doenças permanece limitado. A introdução recente da noção de epigenética no campo psiquiátrico parece exercer a função estratégica de ressignificar a limitação dos resultados encontrados, redescrevendo a importância de cada fator causal na cadeia de constituição patológica e contribuindo para a emergência de um novo modelo etiológico dos transtornos mentais. A partir de estudos genéticos e da investigação dos processos moleculares cerebrais, o novo modelo começa a se constituir e promete dar novo fôlego à difícil e incessante busca pela explicação da origem das doenças. Trata-se de um modelo emergente, que vem ganhando força especialmente na última década, com a proliferação de estudos baseados na suposição de que a interação entre a carga genética e as influências ambientais pode determinar a formação dos transtornos mentais.

Diferentemente da argumentação apresentada nos artigos consultados, não interpretamos a valorização da interação entre gene e ambiente como um resultado necessário ou uma evidência científica alcançada diretamente a partir das pesquisas neurocientíficas. Pelo contrário, a introdução da noção de epigenética e a reorganização das principais hipóteses etiológicas vigentes no campo psiquiátrico contemporâneo surgem no contexto de decepção com o projeto de determinação biológica dos fenômenos mentais. Uma das mais fundamentais apostas dos pesquisadores, a identificação de genes como os primeiros marcadores biológicos dos transtornos, não trouxe os resultados esperados. $\mathrm{O}$ artigo de revisão do GWAS (2009) aponta para a incapacidade de verificação de uma causalidade genética simples e para o aumento da complexidade das próprias hipóteses investigadas. Além disso, as poucas associações reveladas nas primeiras pesquisas não foram facilmente confirmadas em pesquisas subsequentes.

A limitação dos resultados das pesquisas é reinterpretada a partir da noção de epigenética. $\mathrm{O}$ conceito surgido nos anos 40 é retomado e, a partir da década de 90, passa a ser utilizado para compor um novo modelo etiológico das doenças, no qual a interação entre a herança genética e as influências ambientais é responsável pela formação da vulnerabilidade à doença. As pesquisas epidemiológicas em psiquiatria também começam a adotar essa hipótese, de forma que o objetivo inicial de discriminar a influência hereditária e as influências ambientais, que caracterizavam a pesquisa epidemiológica, começa a ceder lugar à investigação da interação gene-ambiente. Portanto, a hipótese epigenética vem se destacando como 
operador conceitual importante e, mais fundamental, capaz de dar novo sentido aos resultados inconclusivos tanto das pesquisas genéticas como das pesquisas epidemiológicas. A partir dessa hipótese, a genética e a variação ambiental são entendidas não como fatores que determinam diretamente a doença, mas como contribuições discretas e probabilísticas à formação psicopatológica.

Autores como Lock (2007), Rose (2007) e Lemke (2007) examinam, em diferentes contextos, a mesma transformação no conhecimento biomédico que verificamos nos artigos neurocientíficos analisados neste trabalho. A partir da ausência das esperadas evidências científicas das pesquisas biomédicas mais deterministas, novas hipóteses e formas de investigação começaram a ser elaboradas, considerando a complexidade dos fenômenos patológicos e, especialmente, a combinação entre a herança biológica e a interação entre organismo e meio como um modelo mais genuíno e factível para o saber biomédico. Lock (2007) sugere que as transformaçôes recentes na biologia molecular são da ordem de uma mudança de paradigma, na medida em que as "trajetórias biológicas não são mais pensadas como necessariamente lineares ou unidirecionais" (LOCK, 2007, p. 63). Para a autora, ainda que boa parte das pesquisas biomédicas mantenha como estratégia o reducionismo e acabe por resvalar em simplificações, a complexidade biológica não pode mais ser negada e a caracterização da biologia molecular como essencialmente reducionista e determinista não faria jus às novas formas de abordagem da doença.

Rose (2007) identifica a mesma transformação epistemológica no campo das pesquisas genéticas, de forma que o determinismo genético mais simples, exemplificado pelo paradigma do "gene para" determinada doença, que dominou as pesquisas moleculares dos anos 60 até o final do século XX, começa a ser reformulado. A partir da virada do século, a hipótese da vulnerabilidade genética começa a se destacar no conjunto das pesquisas genômicas, dando ensejo a novas formas de compreender e manejar a doença. Se os genes não são mais "destino, mas oportunidade” (ROSE, 2007, p. 147), novas práticas e intervenções médicas podem ser derivadas do emergente conhecimento sobre a vulnerabilidade biológica, especialmente aquelas que pretendem antecipar e prever desfechos patológicos, como o screening genético, o diagnóstico precoce, a investigação da especificidade genética na resposta aos medicamentos, etc. 
A partir dos artigos analisados, constatamos que a hipótese etiológica emergente no campo psiquiátrico é menos determinista e mais probabilística do que imaginavam os próprios pesquisadores ou do que prometiam as primeiras pesquisas neurocientíficas. Com isso, a explicação dos processos de formação dos transtornos parece cada vez mais distante do modelo reducionista mais simples e mais próxima das variações entre vulnerabilidade e resiliência que caracterizam a lógica do risco (CASTEL, 1987; CASTIEL, 1999; ARONOWITZ, 2009; ROSE, 2007, 2010). Se a hipótese da interação gene-ambiente vier a se estabilizar no campo psiquiátrico como principal suposição sobre a etiologia dos transtornos mentais, passaremos a considerar cada vez mais as probabilidades estatísticas e as infinitas possibilidades que cercam o pensamento sobre o risco, e seremos desafiados a avaliar e discutir as diversas implicações éticas que resultam da sua aplicação ao entendimento das patologias mentais.

Além de contribuir para a redefinição das principais hipóteses etiológicas adotadas no campo psiquiátrico, a valorização da noção de epigenética impõe uma reconfiguração tanto do conhecimento genético quanto do projeto determinista e reducionista das neurociências. Com a introdução das análises sobre as variações na expressão do patrimônio genético, os próprios pesquisadores do campo foram forçados a reformular suas principais hipóteses e a considerar de modo crescente a influência do ambiente. Se o ambiente vem a ser valorizado como importante elemento na cadeia causal que, como vimos, não conduz diretamente à doença, mas confere diferentes graus de vulnerabilidade e resiliência, pode-se argumentar a favor da dimensão social no conhecimento biológico contemporâneo. Para Rose (2013), essa transformação não somente exige reformulações conceituais e metodológicas no campo científico, mas implica também abertura para novas relações entre as ciências sociais e humanas e as ciências da vida e, acrescentamos, para interpretações mais nuançadas sobre as neurociências e a psiquiatria contemporânea do que as que estamos habituados a realizar.

De todo modo, ainda que o novo artefato conceitual em voga nas pesquisas neurocientíficas mais recentes venha, mais uma vez, gerando otimismo e reeditando a antiga esperança de compreensão da etiologia das doenças, não é tarefa simples investigar fenômenos epigenéticos e atrelá-los a modificaçōes comportamentais, como também não são óbvias as consequências clínicas que porventura poderão ser derivadas desse tipo de conhecimento. Ainda assim, como 
sugere Singh (2012), a epigenética e as teorias emergentes de desenvolvimento

humano podem estar começando a alterar as fronteiras do que conhecemos como herdado e adquirido, buscando novas formas de compreender os processos de formação patológica e, principalmente, de investigar as contribuições da biologia e do ambiente não como variáveis independentes, mas complementares e integradas na construção da vulnerabilidade às doenças. ${ }^{?}$

\section{Referências}

ABI-RACHED, J.; ROSE, N. The birth of the neuromolecular gaze. History of the Human Sciences, v. 23, n. 1, p. 11-36, 2010.

ARONOWITZ, R. The converged experience of risk and disease. The Milbank Quaterly, v. 87, n. 2, p. 417-442, 2009

BASSET, A.S; SCHERER, S.W.; BRZUSTOWICK, L.M. Copy number variations in schizophrenia: critical review and new perspectives on concepts of genetics and disease. American Journal of Psychiatry, v. 167, n. 8, p. 899-914, 2010.

BORELLI, E. et al. Decoding the epigenetic language of neuronal plasticity. Neuron, v. 60, n. 6, p. 961-974, 2008.

CASTIEL, L.D. A medida do possivel... saúde, risco e tecnobiociências [online]. Rio de Janeiro: Fiocruz, 1999.

DICK, D.M.; RILEY, B.; KENDLER, K.S. Nature and nurture in neuropsychiatric genetics: where do we stand? Dialogues in Clinical Neuroscience, v. 12, n. 1, p. 7-23, 2010.

DUDLEY, K. et al. Epigenetics mechanisms mediating vulnerability and resilience to psychiatric disorders. Neuroscience and Biobehavioral Reviews, v. 35, n. 7, p. 1.544-1.551, 2011. EHRENBERG, A. Le sujet cérébral. Esprit, n. 309, p. 130-155, 2004.

FOLEY, D. et al. Prospects for epigenetic epidemiology. American Journal of Epidemiology, v. 169, n. 4, p. 389-400, 2009.

GERSHON, E.S.; ALLIEZ-RODRIGUEZ, N.; LIU, C. After GWAS: searching for genetic risk for schizophrenia and bipolar disorder. American Journal of Psychiatry, v. 168, n. 3, p. 253-256, 2011.

GOTTESMAN, I.; HANSON, D. Human development: biological and genetic processes. Annual Review Psychology, v. 56, p. 263-286, 2005.

GRIFFITH, J.; MAHLER, H. DNA ticketing theory of memory. Nature, v. 223, n. 5206, p. 580-582, 1969.

GWAS Psychiatric Consortium Coordinating Committe. Genomewide Association Studies: history, rationale, and prospects for psychiatric disorders. American Journal of Psychiatry, v. 166, n. 5, p. 540-556, 2009. 
HAIG, D. The (dual) origin of epigenetics. Cold Spring Harbor Symposia on Quantitative Biology, v. LXIX, 2004.

HEALY, D. The creation of psychopharmacology. USA: Harvard University Press, 2002.

HOLLIDAY, R. Epigenetics. A historical overview. Epigenetics, v. 1, n. 2, p. 76-80, 2006.

HOLLIDAY, R.; PUGH, J. DNA modification mechanisms and gene activity during development. Science, v. 187, n. 4173, p. 226-232, 1975.

HORWITZ, A. Creating mental illness. USA: The University of Chicago Press, 2002.

HORWITZ, A.; GROB, G. The checkered hstory of American Psychiatric Epidemiology. The Milbank Quarterly, v. 89, n. 4, p. 628-657, 2011.

HUXLEY, J. Epigenetics. Nature, v. 177, p. 806-808, 1956.

INSEL, T.; QUIRION, R. Psychiatry as a clinical neuroscience discipline. JAMA, v. 294, n. 17 , p. $2221-2224,2005$.

JABLONKA, E. Epigenetic epidemiology. International Journal of Epidemiology, v. 33, n. 5, p. 929-935, 2004.

JIRTLE, R.; SKINNER, M. Environmental epigenomics and disease susceptibility. Nature Reviews: Genetics, v. 8, n. 4, p. 253-262, 2007.

KIM, Y. et al. Schizophrenia genetics: where next? Schizophrenia Bulletin, v. 37, n. 3, p. 456-463, 2011.

LEMKE, T. Susceptible individuals and risky rights: dimensions of genetic responsibility. In: BURRI, R.V.; DUMIT, J. (Eds.). Biomedicine as culture: instrumental practices, technoscientific knowledge, and new modes of life. London: Routledge, 2007

LOCK, M. The future is now: locating biomarkers for dementia. In: BURRI, R.V.; DUMIT, J. (Eds.). Biomedicine as culture: instrumental practices, technoscientific knowledge, and new modes of life. London: Routledge, 2007.

MAYES, R.; HORWITZ, A. DSM-III and the Revolution in the Classification of Mental Illness. Journal of the History of the Behavioral Sciences, v. 41, n. 3, p. 249-267, 2005.

MUNAFÓ, M. Candidate gene studies in the $21^{\text {st }}$ century: meta-analysis, mediation, moderation. Genes, Brain and Behaviour, n. 5, supl. 1, p. 3-8, 2006.

MURGATROYD, C.; SPENGLER, D. Epigenetics of early child development. Frontiers in Psychiatry: Child and Neurodevelopmental Psychiatry, v. 2, p. 1-15, 2011.

NANNEY, D. Epigenetic control systems. Proc Nat Acad Sci USA, v. 44, n. 7, p. 712-717, 1958.

NESTLER, E. Epigenetic mechanisms in psychiatry. Biological Psychiatry, v. 65, n. 3, p. 189-190, 2009.

$\mathrm{OH}$, G.; PETRONIS, A. Environmental studies of schizophrenia through the prism of epigenetics. Schizophrenia Bulletin, v. 34, n. 6, p. 1122-1129, 2008. 
OS, J.; RUTTEN; POULTON. Gene-environment interactions in schizophrenia: review of epidemiological findings and future directions. Schizophrenia Bulletin, v. 34, n. 6, p. 1066-1082, 2008.

RIGGS, A. X inactivation, differentiation and DNA methylation. Cytogenetics Cell Genet, v. 14 , n. 1, p. 9-25, 1975.

ROSE, N. 'Screen and Intervene': governing risky brains. History of the Human Sciences, v. 23, n. 1, p. 79-105, 2010.

ROSE, N. Genomic susceptibility as an emergent form of life? Genetic testing, identity, and the remit of medicine. In: BURRI, R.V.; DUMIT, J. (Eds.). Biomedicine as culture: instrumental practices, technoscientific knowledge, and new modes of life. London: Routledge, 2007.

ROSE, N. The Human Sciences in a Biological Age. Theory, Culture, and Society, v. 30, n. 1, p. 3-34, 2013.

ROSE, N.; ABI-RACHED, J. Neuro. The New Brain Sciences and the Management of the Mind. Princeton: Princeton University Press, 2013.

ROTH, T.; SWEATT, D. Annual Research Review: epigenetic mechanisms and environmental shaping of the brain during sensitive periods of development. Journal of Child Psychology and Psychiatry, v. 52, n. 4, p. 398-408, 2011.

RUTTEN, B.; MILL, J. Epigenetic mediation of environmental influences in major psychotic disorders. Schizophrenia Bulletin, v. 35, n. 6, p. 1045-1056, 2009.

RUTTER, M.; MOFFIT; CASPI. Gene-environment interplay and psychopathology: multiple varieties but real effects. Journal of Child Psychology and Psychiatry, v. 43, n. 3/4, p. 226-261, 2006.

SHORTER, E. A History of Psychiatry. From the Era of the Asylum to the Age of Prozac. New York: Jonh Wiley \& Sons, 1997.

SUlLIVAN, P. The Psychiatric GWAS Consortium: big science comes to psychiatry. Neuron, v. 68, n. 2, p. 182-186, 2010.

SWEATT, J. Experience-dependent epigenetic modifications in the central nervous system. Biological Psychiatry, v. 65, n. 3, p. 191-197, 2009.

TSANKOVA, N. et al. Epigenetic regulation in psychiatric disorders. Nature Reviews: Neuroscience, v. 8, n. 5, p. 355-367, 2007.

VISSCHER, P. et al. Five Years of GWAS Discovery. The American Journal of Human Genetics, v. 90, n. 1, p. 7-24, 2012.

WADDINGTON, C. The Epigenotype. International Journal of Epidemiology, v. 41, n. 1, p. 10-13, 2012.

WONG, A.H.; GOTTESMAN, I.I.; PETRONIS, A. Phenotypic differences in genetically identical organisms; the epigenetic perspective. Human molecular Genetics, v. 14, n. 1, p. $11-18,2005$. 
${ }^{1} \mathrm{O}$ que nomeamos como "neurociências" faz referência a um projeto multidisciplinar que reúne diversas disciplinas, técnicas de investigação e temas de pesquisa. A despeito da enorme dificuldade envolvida na determinação histórica do surgimento das neurociências, Abi-Rached e Rose (2010) sugerem que a inauguração do projeto neurocientífico remonta aos EUA do pós-guerra. Outros autores, como Shoter (1997), localizam o marco inaugural do projeto neurocientífico no I Congresso Internacional de Psiquiatria, realizado em Paris, em 1950. De todo modo, foi nos EUA das décadas de 60 e 70 que tal projeto tomou corpo, recebeu incentivo financeiro e institucional e, com isso, encontrou condiçóes para se desenvolver. Paralelamente, trajetórias similares podem ser identificadas no Reino Unido e na França. Ver Abi-Rached e Rose (2010).

${ }^{2}$ A metilação do DNA é um dos mecanismos epigenéticos mais pesquisados na área e consiste, em linhas gerais, na adição de um elemento químico (um grupo metil) a uma região específica do DNA. Segundo as hipóteses atuais, a metilação é um processo comum na fase embrionária e ao longo do desenvolvimento, e tem como principal consequência o silenciamento de determinada região do DNA, impedindo a síntese de proteínas que caracterizaria sua ativação. Dessa forma, esse mecanismo epigenético produziria alterações estáveis na produção de proteínas daquela região do DNA, alterando de forma permanente a expressão da herança genética (GOTTESMAN; HANSON, 2005; BORRELLI et al., 2008; RUTTEN; MILL, 2009; SWEATT, 2009).

${ }^{3} \mathrm{O}$ Psychiatric GWAS Consortium inclui praticamente todos os estudos realizados no âmbito do GWAS (Genome-wide association studies) que reúnem informação sobre esquizofrenia, transtorno bipolar, transtorno depressivo maior, TDAH e autismo. Agregando 121 pesquisadores e cerca de 61 instituiçōes, essa rede de pesquisa tem como objetivos: 1) realizar meta-análises dos dados reunidos para as categorias diagnósticas especificadas; 2) realizar análises de combinaçôes de dois ou mais transtornos e de sintomas que sejam comuns a mais de uma categoria (como depressão e psicose), bem como analisar fenótipos alternativos; e 3) realizar análises de comorbidades como uso de álcool, nicotina e transtorno de uso de drogas ilícitas, cujas categorias podem ser investigadas por meio do estudo de diversos grupos de sujeitos (GWAS, 2009).

${ }^{4}$ Sobre a história e o funcionamento do Psychiatric GWAS Consortium Coordinating Committe, ver Sullivan (2011).

${ }^{5}$ De fato, os resultados das pesquisas genéticas realizadas no âmbito do GWAS para patologias comuns e complexas são controversos, uma vez que alguns pesquisadores consideram a limitação dos resultados encontrados uma indicação de fracasso do projeto. Neste sentido, questiona-se a suposição de que a herança genética desempenhe papel importante na determinação do risco para doenças comuns (não diretamente genéticas) e que o entendimento dos fatores genéticos cujos efeitos são muito limitados viria a contribuir para avanços diagnósticos, terapêuticos e clínicos. Para uma discussão sobre o suposto "fracasso" e as conquistas do projeto, ver Visscher et al. (2012).

${ }^{6}$ Em artigo de revisão sobre a história da epidemiologia psiquiátrica norte-americana, Horwitz e Grob criticam os resultados contraditórios e pouco seguros encontrados por essas pesquisas. Os autores atribuem a falta de conclusões significativas principalmente à dificuldade de classificação dos transtornos mentais, que tornaria as pesquisas carentes de validade e as impossibilitaria de contribuir, de fato, para a compreensão da etiologia das doenças mentais (HORWITZ; GROB, 2011).

${ }^{7}$ Disponível em: <www.eu-gei.eu> 
${ }^{8} \mathrm{~A}$ integração gradual de conhecimento entre a epidemiologia e a genética humana estaria levando a constituição de uma nova disciplina, a epidemiologia genética, dedicada ao entendimento não mais da discriminação, mas da interação entre os diversos fatores que contribuem para a formação da doença. Nesta área emergente, a hipótese epigenética desempenha um papel fundamental (JABLONKA, 2004; FOLEY et al., 2008; OS; RUTTEN; POULTON, 2008; OH; PETRONIS, 2008; PROJETO EU-GEI; DICK; RILEY; KENDLER, 2010).

${ }^{9}$ L.R. Freitas-Silva participou da concepção, análise dos dados e redação do artigo. F.J.G. Ortega participou da redação e da revisão crítica do artigo. 


\section{Abstract}

\section{Epigenetics as new etiological hypothesis in the contemporary psychiatric field}

In recent decades, neuroscientific theories began to be adopted as central to the etiology of mental disorders explanation. Aiming to find the foundations of disorders, investigations took prioritized genetic load and brain functioning. From the valuation of biological determination of diseases and the emergence of various technologies of medical research, one has suggested the possibility that the causes of disorders were finally understood. However, several difficulties and challenges mark the neuroscientific project biological foundation of disease etiology. The recent introduction of the notion of epigenetics in the psychiatric field has been considered essential to renew the hope of understanding the etiology of disorders. From the analysis of review articles, this article aims to examine the appropriation of the concept of epigenetics by contemporary psychiatric field, identifying their origins and describing their main characteristics, and reflect on the consequences of their adoption. Besides contributing to the redefinition of etiological theories in the psychiatric field, the notion of epigenetics imposes a reconfiguration of genetic knowledge and, to some extent, the deterministic and reductionist design of biological foundation of mental disorders itself, allowing for more nuanced interpretations of neuroscience and contemporary psychiatry.

> Key words: Biological psychiatry; neuroscience; etiology. 